\title{
Reconstitution of human TFIIA activity from recombinant polypeptides: a role in TFIID-mediated transcription
}

\author{
Xiaoqing Sun, Dongmin Ma, Michael Sheldon, Kam Yeung, and Danny Reinberg ${ }^{1}$ \\ Howard Hughes Medical Institute, Department of Biochemistry, Robert Wood Johnson Medical School, University \\ of Medicine and Dentistry of New Jersey, Piscataway, New Jersey 08854-5635 USA
}

\begin{abstract}
Human TFIIA activity is composed of three subunits $(\alpha, \beta, \gamma)$. Here we report the isolation of a human cDNA clone encoding the $\gamma$-subunit and the reconstitution of TFIIA activity from recombinant polypeptides (holo-TFIIA). Protein-protein interaction analysis established that the $\beta$ and $\gamma$ subunits of TFIIA interact with the TBP component of TFIID. The $\alpha$-subunit is recruited into the complex by association with the $\gamma$-subunit. Functional studies indicate that recombinant TFIIA stimulates basal TFIID-dependent transcription but is without effect on TBP-dependent transcription. Our studies indicate that TFIIA not only functions by physically removing negative components present in TFIID (antirepression), as demonstrated previously, but that it can stimulate basal transcription through components of the TFIID complex. Holo-TFIIA also stimulated activation of transcription in vitro as well as in vivo in transfected HeLa cells.
\end{abstract}

[Key Words: Human TFIIA activity; recombinant polypeptides; TFIID-dependent transcription; transcriptional activation]

Received August 8, 1994; revised version accepted August 30, 1994.

The process of transcription initiation on class II promoters is enormously complex, requiring concerted interactions between at least seven protein factors and RNA polymerase II-an assortment of $>30$ polypeptides. This family of factors is collectively referred to as the general or basal transcription factors (GTFs) and includes TFIIA, TFIIB, TFIID, TFIIE, TFIIF, TFIIH, and TFIIJ (for review, see Zawel and Reinberg 1993).

Prior to the formation of the first phosphodiester bond in the nascent transcript, the GTFs assemble at the promoter through a highly ordered pathway and, in doing so, facilitate loading of RNA polymerase II (RNAPII) onto the DNA. TFIID appears to be the only GTF that possesses sequence-specific DNA-binding activity. All of the other factors enter into the assembly pathway via protein-protein interactions (Zawel and Reinberg 1993). The TFIID-DNA complex is stabilized by TFIIA and recognized by TFIIB (Buratowski et al. 1989; Maldonado et al. 1990; Lee et al. 1992; Imbalzano et al. 1994). Independent of TFIIA, the DB complex is recognized by RNAPII/ IIF, after which TFIIE, TFIIH, and TFIIJ each enter sequentially (Flores et al. 1991, 1992; Zawel et al. 1993). The complexity of this pathway provides a multitude of potential steps that might serve as targets for regulatory factors (Choy and Green 1993; Drapkin et al. 1993). In agreement with this contention, recent studies indicate direct interactions between numerous transcriptional

${ }^{1}$ Corresponding author. regulators and several members of the basal apparatus including the TBP component of TFIID (Stringer et al. 1990), TFIIB (Lin et al. 1991), TFIIF (Kephart et al. 1994), and TFIIH (Xiao et al. 1994 ). To fully understand the significance of these interactions, it has been our goal to define, physically and biochemically, each of the intermediates generated during preinitiation complex formation.

Previous studies have established that TFIIA can enter at any stage of preinitiation complex formation (Cortes et al. 1992). The entry of TFIIA is mediated, at least in part, through a direct interaction with the TBP subunit of TFIID and is independent of DNA (Buratowski et al. 1989; Cortes et al. 1992; Coulombe et al. 1992; Lee et al. 1992). TFIID is a multisubunit factor composed of the TATA-binding protein (TBP) and TBP-associated factors (TAFs) (Pugh and Tjian 1990; Lewin 1990). TAFs are important in activation of transcription yet appear to play no role in basal transcription /Chiang et al. 1993; Goodrich et al. 1993; Hoey et al. 1993; Ruppert et al. 1993; Weinzierl et al. 1993; Yokomori et al. 1993b; Verrijzer et al. 1994; for reviews, see Gill and Tjian 1992; Tjian and Maniatis 1994). The effects on transcription by TFIIA seem to be mediated through the TFIID complex; transcription reactions reconstituted with TBP (in the absence of TAFs) are not affected by TFIIA (Cortes et al. 1992). These observations suggest that TFIIA may have a regulatory role in transcription. TFIIA plays a paramount role in transcription, as evidenced by the finding that 
TFIIA is essential for viability in yeast because of its involvement in transcription by RNAPII (Ranish et al. 1992). The possible participation of TFIIA in activation of transcription (including antirepression), rather than in basal transcription, is supported by the finding that TFIIA interacts with $\mathrm{TAF}_{\mathrm{II}} 110$ (Yokomori et al. 1993a).

TFIIA activity isolated from human cells is composed of three subunits with apparent molecular masses of 37 $(\alpha), 19(\beta)$, and $13(\gamma) \mathrm{kD}$ (Cortes et al. 1992; Coulombe et al. 1992). We and others have previously reported the isolation of cDNA clones encoding the largest subunit of TFIIA (DeJong and Roeder 1993; Ma et al. 1993; Yokomori et al. 1993a). These studies resulted in the finding, both in human and Drosophila, that the two largest subunits of TFIIA ( $\alpha$ and $\beta$ ) are encoded by a single gene and are probably generated by protein processing. Interestingly, yeast TFIIA activity contains two polypeptides, TOA1 and TOA2, each encoded by a different gene (Ranish et al. 1992; Ranish and Hahn 1992). The $\alpha$ and $\beta$ subunits of human TFIIA have substantial sequence similarity to the amino and carboxyl termini of TOA1, respectively. We now report the isolation of a human cDNA encoding the smallest subunit $(\gamma)$ of TFIIA. Amino acid sequence analysis demonstrates significant homology with TOA2. To define the role of TFIIA in transcription, we have reconstituted TFIIA activity from recombinant polypeptides. Functional analysis indicated that TFIIA is not a general (basal) transcription factor, as the recombinant factor (holo-TFIIA) has no apparent role in basal transcription. However, holo-TFIIA can interact with TBP and stimulate TFIID-dependent transcription.

\section{Results}

Molecular cloning of the $\gamma$-subunit of TFIIA (TFIIA- $\gamma$ )

TFIIA activity was purified using conventional chromatography, combined with TBP affinity chromatography. The procedure described previously demonstrated that human TFIIA activity is composed of three polypeptides (Cortes et al. 1992; Coulombe et al. 1992; Ma et al. 1993). A cDNA clone encoding the two largest subunits has been isolated using "reverse genetics" and conventional cloning techniques (DeJong and Roeder 1993; Ma et al. 1993; Yokomori et al. 1993a). Isolation of a cDNA encoding the smallest subunit of human TFIIA was accomplished by obtaining peptide sequences derived from the isolated $\gamma$-subunit and was aided by the analysis of the amino acid sequence of the Drosophila TFIIA- $\gamma$ subunit (dTFIIA- $\gamma$, gift of Dr. R. Tjian, University of California, Berkeley) and the yeast TOA2.

Comparison of amino acid sequence between the dTFIIA- $\gamma$ subunit and yeast TOA2 revealed regions with extensive homology. Degenerate oligonucleotides spanning residues $65-74$ and 92-98 of the dTFIIA- $\gamma$ subunit (Yokomori et al., this issue) were synthesized and used to screen a human cDNA library. The complete nucleotide sequence of the longest cDNA isolated is shown in Figure 1A. The nucleotide sequence of the cDNA predicts an open reading frame encoding a polypeptide of 109 amino acids, with a calculated molecular mass of 12,456 daltons and a pI of 6.6. Amino acid sequence analysis of the human cDNA clone revealed a high degree of conservation with the dTFIIA- $\gamma$ subunit $185 \%$ homology, $77 \%$ identity) and yeast TOA2 164\% homology, $42 \%$ identity) (Fig. 1B,C).

The recombinant protein was expressed in Escherichia coli using the pET15(b) expression vector. The polypeptide was tagged at the amino terminus with six consecutive histidines for rapid purification. Polyclonal rabbit antibodies were raised against the purified recombinant protein and used to verify whether the isolated cDNA is the authentic TFIIA- $\gamma$ subunit. These antibodies specifically recognize a $13-\mathrm{kD}$ polypeptide that copurifies with TFIIA activity as detected in a Western blot analysis (data not shown; see below).

Next, we tested whether antibodies raised against the recombinant polypeptide are specific for interaction with the DNA-protein complex containing native TFIIA. The formation of a transcription-competent complex is a highly ordered process featuring numerous intermediates that can be resolved using the gel mobility shift assay (Buratowski et al. 1989; Maldonado et al. 1990). An early intermediate is the association of TBP with the TATA motif. The TBP-DNA-protein complex is recognized by TFIIA generating the TA complex /see Fig. 2). This complex was, as expected, not affected by anti-TFIIB antibodies (lane 5). However, the addition of antibodies against recombinant TFIIA- $\alpha$ polypeptide resulted in a supershift of this complex (lane 4). Similarly, the addition of antibodies against the recombinant 13$\mathrm{kD}$ polypeptide also resulted in a supershifted complex (cf. lane 3 with lanes 6-8). This supershifted complex migrated faster than the complex supershifted by antiTFIIA- $\alpha$ antibodies (cf. lane 4 with lanes 6-8). More importantly, the effect of the antibodies against the $13-\mathrm{kD}$ polypeptide was specific and due to the presence of TFIIA, as the antibodies were without effect on the migration of complexes devoid of TFIIA and containing Gal4, YY1, or TBP and Dr1 (lanes 9-14).

The above results demonstrate that the isolated cDNA clone encodes the $\gamma$-subunit of TFIIA. Moreover, the gel mobility shift studies demonstrate that the $\gamma$-subunit of TFIIA is an integral component of the TA complex.

\section{Reconstitution of TFIIA activity from recombinant polypeptides}

Having established that the isolated cDNA clone encodes the $\gamma$-subunit of TFIIA, we attempted to reconstitute TFIIA activity with recombinant polypeptides. The isolation of a cDNA clone encoding the two largest subunits of TFIIA was reported previously (DeJong and Roeder 1993; Ma et al. 1993; Yokomori et al. 1993a). The $\alpha$ - and $\beta$-subunits are encoded by one gene and are most likely generated by protein processing. We have found previously that the recombinant precursor polypeptide (p56), containing $\alpha$ and $\beta$, can reconstitute TFIIA-binding activity in the presence of native $\beta$ - and $\gamma$-subunits (Ma et al. 1993). Here, we observed that a TA complex could 

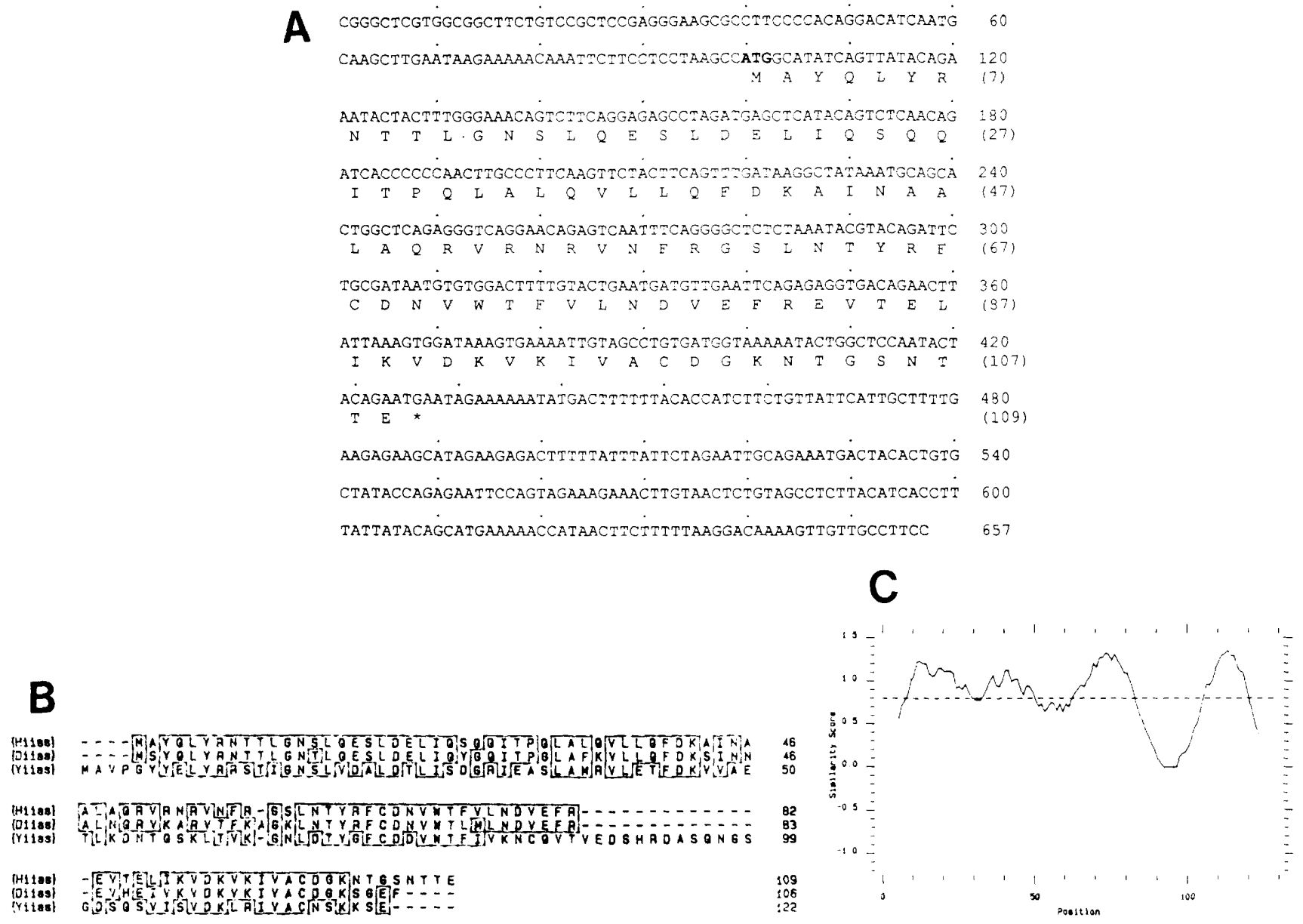

Figure 1. Nucleotide sequence of a cDNA encoding the small subunit of TFIIA. $(A)$ Nucleotide and predicted amino acid sequence of the small subunit of TFIIA. (B) Amino acid sequence comparison between human, Drosophila, and yeast small subunits of TFIIA using the GCG program. The amino acids inside the boxes represent conserved residues. (C) Similarity plot of the comparison in $B$. The peaks above the broken line represent the extent of regions of homology. The single low point below the broken line corresponds to amino acids $87-100$ in yeast TOA2, which are absent in the human and Drosophila TFIIA- $\gamma$ subunit.

be formed with recombinant $\gamma$ and p56 $(\alpha / \beta)$ polypeptides (Fig. 3C, lanes 8-10). Surprisingly, we found that when equivalent molar amounts of native and recombinant TFIIA were compared, the activity elicited by recombinant TFIIA was lower than that of the native factor, as measured by the levels of TA complex formed (Fig. 3C, cf. lane 3 with lanes 8-10; data not shown). Recovery of TFIIA activity with recombinant p56 and pl3 required the polypeptides to be denatured and renatured together. We could not increase the activity of recombinant TFIIA by varying the ratio of the p56/pl3 subunits (Fig. 3C; data not shown). It is possible that high levels of TFIIA activity require mature $\alpha$ and $\beta$ polypeptides rather than the precursor $\mathrm{p} 56$.

Recombinant $\alpha$ and $\beta$ polypeptides were produced in vitro from the p56 precursor as described in Material and Methods. Presently, we do not know the precise $\alpha-\beta$ cleavage point; therefore, we refer to these polypeptides as "synthetic" $\alpha$ and $\beta$. The synthetic $\alpha$-subunit extended from the amino terminus to residue 300 of p56 and included all peptide sequences derived from the hu- man $\alpha$-subunit (Fig. 3A). The synthetic $\beta$-subunit included the carboxy-terminal residues extending from amino acid 301 of p56, including the peptides sequence derived from the human $\beta$-subunit (see Fig. 3A).

The synthetic $\alpha$ and $\beta$ polypeptides and the recombinant $\gamma$-subunits were purified to homogeneity (Fig. 3B). Equimolar amounts of each of these polypeptides were mixed and assayed for their ability to form the TA complex. Under these conditions, two DNA-protein complexes were observed (Fig. 3C). The slower complex migrated with a mobility similar to the TA complex formed with recombinant p56 and $\gamma$-subunit, yet slower than the complex formed with native TFIIA. The other complex migrated faster (Fig. 3C, lanes 11-13). The overall activity of recombinant TFIIA /reconstituted from individual subunits) appears significantly increased with respect to the TFIIA containing the precursor p56 polypeptide and was similar to the human native factor (data not shown; see below).

A possible interpretation of the result obtained with individual subunits was that the faster migrating com- 


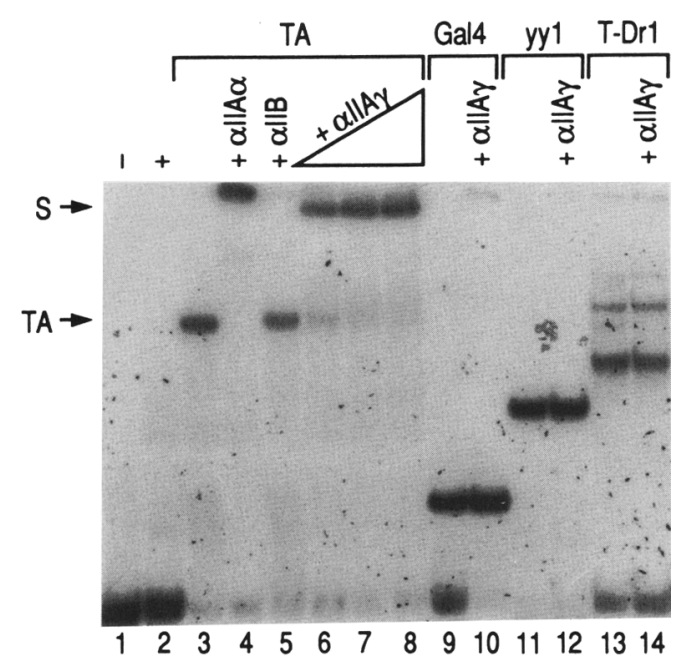

Figure 2. TFIIA antibody can specifically supershift TA complex in the gel mobility shift assay. DNA-protein complexes were formed on DNA fragments containing the TATA motif of the adenovirus major late promoter as described in Materials and methods. Also oligonucleotide probes containing the Gal4 and YY1 DNA-binding sites were used as indicated /Hariharan et al. 1991; Park and Atchison 1991; Shi et al. 1991; Flanagan et al. 1992). The TA, Gal4, YY1, T-Dr ${ }_{1}$, and supershifted complexes were formed on the labeled probe and separated on a native polyacrylamide gel as described in Materials and methods. The protein amounts used are $40 \mathrm{ng}$ of TBP, $10 \mathrm{ng}$ of Gal4(1-94), $100 \mathrm{ng}$ of His-tagged YY1, and $50 \mathrm{ng}$ of $\mathrm{Dr}_{1}$ (from HeLa cells, Inostroza et al. 1992). The migration of the different DNA-protein complexes is indicated at the left. (S) Supershifted TA complex attributable to the association of the antibodies with TFIIA in the complex. Additions of protein factors are indicated at the top. $\alpha$ IIA $\alpha, \alpha I I A \gamma$, and $\alpha$ IIB indicates antibodies against the $\alpha$ and $\gamma$ subunits of TFIIA and against TFIIB, respectively.

plex represented an incomplete TA complex formed with a subset of TFIIA subunits. Consistent with this view, the combination of the $\beta$ and $\gamma$ subunits produced a TBP-dependent DNA-protein complex (Fig. 4, cf. lane 7 with 8 , I complex|. This complex migrated faster than the one formed with native (Fig. 4, lane 2, complex nTA) or recombinant (Fig. 4, lane 4, complex rTA) TFIIA subunits. The I complex contained TBP and the $\gamma$-subunit of TFIIA, as antibodies against these polypeptides supershifted the complex (Fig. 4, lanes 9,10). The complex was specific for the TATA motif, as the addition of excess oligonucleotide containing a wild-type, but not a mutant, TATA motif eliminated the complex (data not shown). The I complex appears to be missing the TFIIA $\alpha$-subunit, as the addition of this polypeptide resulted in the disappearance of the I complex and the production of three new complexes (lane 12). The faster and least abundant of these complexes comigrated with the TA complex formed with all three TFIIA subunits. The other two complexes $(\mathrm{Cl}$ and $\mathrm{C} 2)$ have a retarded mobility. These complexes were dependent on TBP (lane 11) and contained TBP and the $\gamma$-subunit of TFIIA (lanes 13,14), as antibodies against these polypeptides supershifted all complexes. The differential migration of the TA complex $(\mathrm{C} 1, \mathrm{C} 2$, and those formed with recombinant and native TFIIA) is surprising but perhaps indicative of different conformations of TFIIA within the TA complex. This is supported by the fact that when the three subunits of TFIIA are added simultaneously to the DNAbinding assay, a predominant complex is formed that exhibits a similar mobility to the complex formed with native TFIIA (Fig. 4, cf. lanes 2,4). In contrast, if the $\beta$ and $\gamma$ subunits, together with TBP, are added to the DNAbinding assay first, followed by the addition of the $\alpha$-subunit, then the complex acquires different migrations (Fig. 4, lane 12).

\section{TFIIA subunits and TBP interactions}

From the above results it is possible to conclude that TBP, in the presence of DNA (TATA motif), interacts with the $\beta$ and/or $\gamma$ subunits of TFIIA. We extended these studies and analyzed whether an interaction between TBP and p56 $(\alpha / \beta)$ or the $\gamma$-subunit of TFIIA could be demonstrated by immunoprecipitation. The immunoprecipitation experiments shown in Figure 5 were performed with beads containing TBP bound to monoclonal antibodies recognizing the species-specific amino terminus of TBP. These TBP-containing beads were incubated with rIIA, p56 $(\alpha / \beta)$, or $\gamma$-subunit under conditions of different salt concentrations. The coimmunoprecipitates were then washed with buffers of different salt concentrations, as indicated, and the TFIIA subunits eluted with a low $\mathrm{pH}$ glycine buffer. The presence or absence of polypeptides (p56 or $\gamma$ ) was analyzed on a Western blot using antibodies as described in Figure 5.

As shown in the Western blot in Figure 5A, p56 was coimmunoprecipitated by the monoclonal antibodies (lanes 3,5). Immunoprecipitation of p56 was dependent on TBP (lanes 2,4$)$. The extent of the interaction between TBP and p56 could not be augmented by the presence of the $\gamma$-subunit (TFIIA) (Fig. 5A, cf. lanes 3 and 5). Interestingly, Western analysis using anti-TFIIA- $\gamma$ antibodies indicated that TBP also interacts with this polypeptide and that this interaction could be enhanced in the presence of p56 (Fig. 5B). Taken together, the immunoprecipitation studies and the gel mobility shift analyses indicate that the carboxyl terminus of p56 (TFIIA- $\beta$ ) and TFIIA- $\gamma$ interact with TBP.

Previously we demonstrated that TFIIA- $\alpha$ can be an integral component of the preinitiation complex (Ma et al. 1993). Because we found that TFIIA- $\alpha$ does not interact with TBP or DNA (data not shown), we analyzed whether it interacts with the $\beta$ - or $\gamma$-subunit of TFIIA. Western analysis of immunoprecipitations using antiTFIIA- $\gamma$ antibodies demonstrated an interaction between the $\alpha$ and $\gamma$ subunits of TFIIA (Fig. 6A). Under similar conditions we were unable to demonstrate an interaction between the $\gamma$ and $\beta$ subunits (Fig. 6B). These studies suggest that the $\beta$ and $\gamma$ subunits of TFIIA directly contact TBP and that the $\alpha$-subunit contacts the complex through an interaction with the $\gamma$ subunit. Since the precise cleavage point of the precursor polypeptide that 

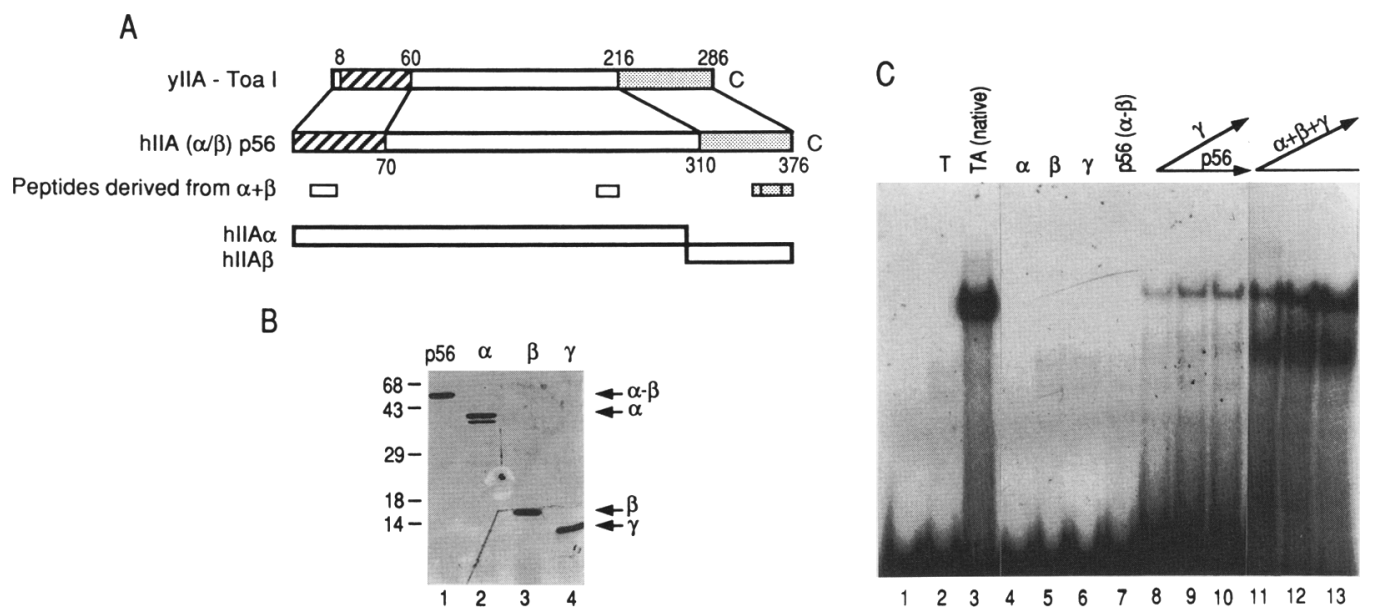

Figure 3. Reconstitution of TFIIA using recombinant proteins. $(A)$ Diagram comparing the yeast TOA1 and human p56 precursor polypeptides. The shaded areas indicate regions of homology between yeast and human proteins. The open and shaded boxes (below) represent peptide sequences obtained from the $\alpha$ and $\beta$ subunits of human TFIIA, respectively, as indicated. The diagram at the bottom represents the synthetic $\alpha$ and $\beta$ subunits. $(B)$ Silver staining of purified recombinant polypeptides. A total of $100 \mathrm{ng}$ of each protein sample was loaded. $(C)$ Gel mobility shift assay of DNA-protein complexes formed with recombinant proteins, $\alpha / \beta($ p 56$)+\gamma$ or $\alpha+\beta+\gamma$, and TBP on the TATA motif of the adenovirus major late promoter (TA). Addition of factor was as indicated. The amount of protein added to the assay was as follows: native TFIIA $(0.2 \mu \mathrm{g}$, DEAE-5PW fraction; Cortes et al. 1992). The amount of p56 and $\gamma$ polypeptides was 3,6 , and 12 pmoles in a 20- $\mu$ l reaction (lanes 8-10). The amount of protein in lanes $11-13$ was 3,6 , and 12 pmoles of each of the $\alpha, \beta$, and $\gamma$ subunits. Twelve picomoles of each factor $(\alpha, \beta, \gamma$, or $\alpha / \beta)$ was added to the reaction in lanes 4-7. Reaction mixtures also contained 1.5 pmole of TBP as indicated. Samples described in lanes 8-10 and lanes 11-13 were mixed, denatured, and renatured together. Renaturation was by dialysis as described in Materials and methods.

yields $\alpha$ and $\beta$ is not known, we cannot rule out the possibility of other interactions.

\section{TFIIA enhances TFIID-dependent transcription}

Having established that TFIIA activity can be reconstituted from recombinant polypeptides we analyzed the effect of TFIIA in basal and activated transcription.

Transcription reactions were reconstituted as described in Materials and methods and contained two DNA templates with identical promoter sequences, but producing transcripts of different sizes. Because of differences in the length of their G-less cassettes, one template directs a transcript of 380 nucleotides (bands labeled + in Figs. 7 and 8 ) and the other template directs a shorter 260-nucleotide transcript (bands labeled - in Figs. 7 and 8). The template producing the longer transcripts contains five GAL4 DNA-binding sites immediately upstream of the TATA motif. These sites serve to target a chimeric GAL4-VP16 fusion protein to the promoter in the activation studies in Figure 8B.

In Figure $7 \mathrm{~A}$ we have examined the effect of addition of recombinant or native TFIIA upon basal transcription (i.e., in the absence of GAL4-VP16) directed by either yeast TBP or highly purified human epitope-tagged TFIID (eTFIID). The addition of human or recombinant TFIIA to transcription reactions reconstituted with highly purified GTFs and TBP was without effect (Fig. 7A, lanes 1-4; also see Fig. 7B). However, when TFIID was used instead of TBP, we found that both human and recombinant TFIIA stimulated transcription (Fig. 7, A,

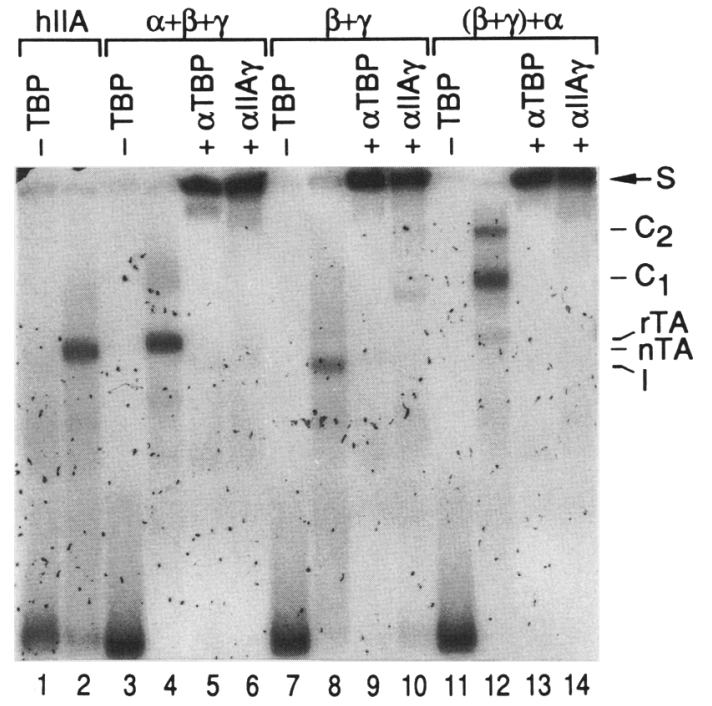

Figure 4. Analysis of DNA-protein complexes formed with subset of TFIIA subunits. Different proteins as indicated at the top were added to the assay. TBP (1.5 pmole) was added to the reactions. TFIIA subunits ( 8.0 pmoles of each) were added, as indicated. The native TFIIA protein fraction used was derived from the gel filtration step $(0.6 \mu \mathrm{g}$; Cortes et al. 1992). In lanes 11-14 the $\beta$ and $\gamma$ subunits were incubated with TBP and DNA for 20 min prior to the addition of the $\alpha$-subunit. After addition of the $\alpha$-subunit the reaction was incubated for $10 \mathrm{~min}$. Antibodies were added after complexes were formed, and the reaction was incubated further for $15 \mathrm{~min}$. TBP was omitted from lanes $1,3,7$, and 11 , as indicated at the top. 

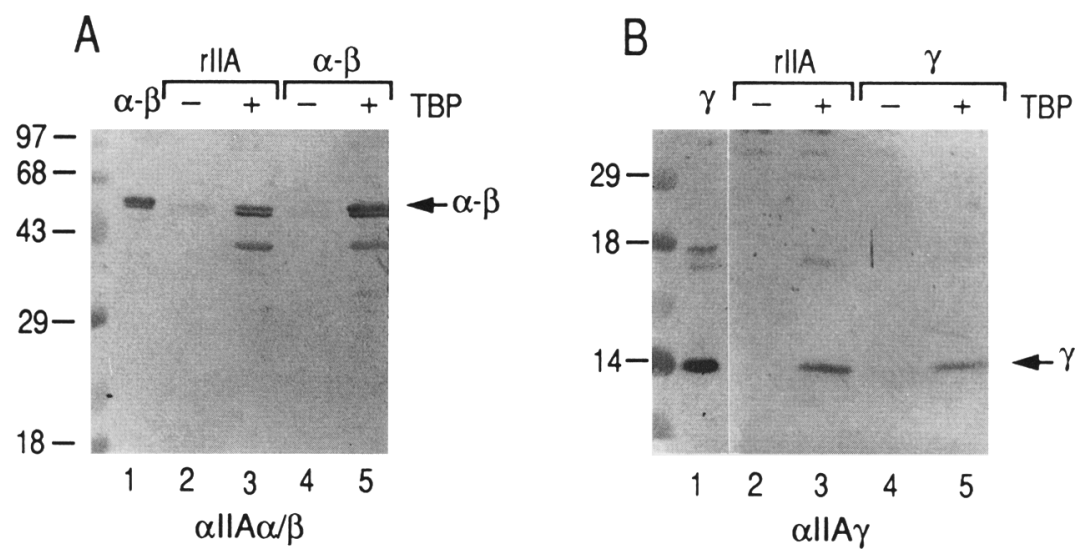

Figure 5. Interaction between TBP and subunits of TFIIA. Coimmunoprecipitation (Co-IP) and Western blot analysis were performed as described in Materials and methods. Monoclonal antibodies against the amino-terminal portion of human TBP were used. $(A)$ Interaction between human TBP and TFIIA- $\alpha / \beta$. The amount of $0.25 \mu \mathrm{g}$ of $\alpha / \beta(\mathrm{p} 56)+\gamma$ or $\alpha / \beta(\mathrm{p} 56)$ was used in the co-IP reaction either in the presence or absence of TBP. Immunoprecipitates were washed with IP buffer containing 1.0 $\mathrm{M} \mathrm{KCl}$. Recombinant $\alpha / \beta$ protein was loaded in lane 1 to serve as a marker. Human TBP was not added to the IP reaction in lanes 2 and 4 . Human TBP was present in the reactions represented in lanes 3 and 5. Antibodies used in the Western blot analysis are indicated at the bottom. $(B)$ Interaction between human TBP and the TFIIA- $\gamma$ subunit. The amount of $0.25 \mu \mathrm{g}$ of $\alpha / \beta(\mathrm{p} 56)+\gamma$ or $\gamma$ was used in the co-IP reaction either in the presence or absence of TBP. Recombinant $\gamma$ protein (100 ng) was loaded in lane 1 to serve as a marker. Human TBP was present in the IP reactions of lanes 3 and 5. Human TBP was not added in the reactions of lanes 2 and 4. Anti-TFIIA- $\gamma$ antibodies were used in the Western blot.

lanes $5-8$, and B). These results are in perfect agreement with our earlier observations demonstrating that the TFIIA effect on transcription is dependent on TFIID (Cortes et al. 1992; Ma et al. 1993).

Our earlier observations led us to hypothesize that
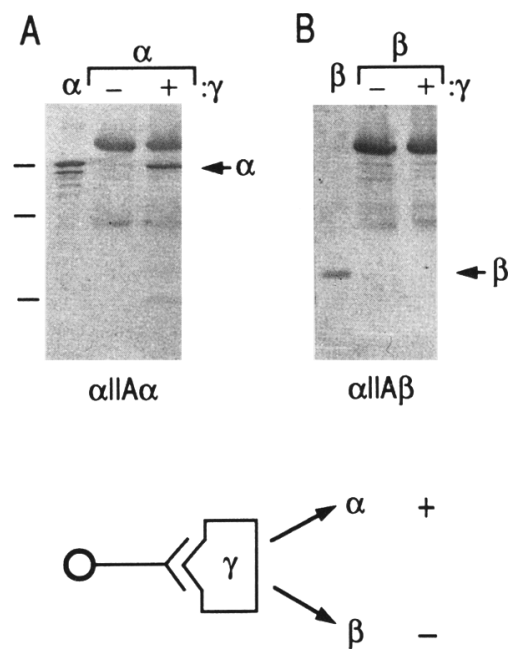

Figure 6. Interaction between subunits of TFIIA. Coimmunoprecipitation experiments were performed as described in Materials and methods. Protein A-purified anti-TFIIA- $\gamma$ antibody and $0.25 \mu \mathrm{g}$ of $\gamma$ protein were used in the analysis. $(A)$ Interaction between TFIIA- $\alpha$ and TFIIA- $\gamma$. The amount of $0.25 \mu \mathrm{g}$ of $\alpha$ protein was used in the immunoprecipitation (IP) reaction either in the presence or absence of $\gamma$ protein (the right and middle lane, respectively). The immunoprecipitates were washed with IP buffer containing $1.0 \mathrm{M} \mathrm{KCl}$. Recombinant $\alpha$ protein $(100 \mathrm{ng})$ was loaded in the left lane as a marker. TFIIA- $\alpha$ antibodies were used in the Western blot. $(B)$ Interaction between TFIIA $\beta$ and TFIIA $\gamma$. The amount of $0.25 \mu \mathrm{g}$ of $\beta$ protein was used in the IP reaction either in the presence or absence of $\gamma$ protein (the right and middle lane, respectively). Immunoprecipitates were washed with IP buffer containing $0.75 \mathrm{M} \mathrm{KCl}$. Recombinant $\beta$ protein (100 ng) was loaded in the left lane as a marker. TFIIA- $\beta$ antibodies were used in the Western blot.
TFIID contains negative components that are displaced as a result of the interaction of TFIIA with the TBP component of TFIID (Cortes et al. 1992). This hypothesis gained support when repressors of transcription, such as $\mathrm{Dr}_{2}$, (Merino et al. 1993), NC1, and NC2 (Meisterernst et al. 1991), and MOT1 (Auble et al. 1994), were identified and shown to interact with TBP (or TFIID). In each case, repression was overcome by the addition of TFIIA. More importantly, addition of $\mathrm{Dr}_{2}$ could impose a requirement for TFIIA in transcription reactions reconstituted with TBP (Ma et al. 1993; Merino et al. 1993). However, in those studies we could not analyze whether TFIIA enhanced transcription by mechanism(s) other than antirepression. The development of methods to purify TFIID to apparent homogeneity enables us to tackle this question. eTFIID (Zhou et al. 1992) was immunopurified as described previously. The TFIID complex was washed with high salt and detergents prior to elution from the column. This step ensured removal of factors, other than TAFs, that interact (associate) with the TFIID complex. TFIID associated factors such as $\mathrm{Dr}_{1}$ (Inostroza et al. 1992), $\mathrm{Dr}_{2}$ (Merino et al. 1993), and TFIIA (Yokomori et al. 1993a) could not be detected by Western blot analysis in the purified eTFIID (Fig. 8A; data not shown). Using eTFIID, we found that the addition of TFIIA (human or recombinant/ resulted in stimulation of transcription (Fig. 7A, lanes 9-12). This stimulation required each of the TFIIA subunits (data not shown; see below), and the extent of stimulation was similar to that observed with partially purified TFIID (cf. lanes 5-8 with lanes 9-12). The amounts of TBP (recombinant, TFIID or eTFIID) added to the assay were similar, as determined by Western blot analysis. These results, therefore, establish that recombinant TFIIA stimulates TFIID-mediated transcription. The fact that the levels of transcription observed with eTFIID (or TFIID) were comparable to those observed with TBP, in the absence of TFIIA (Fig 7B), strongly suggests that TFIIA not only functions by physically removing negative components present in TFIID (antirepression) but that it can stimulate basal 


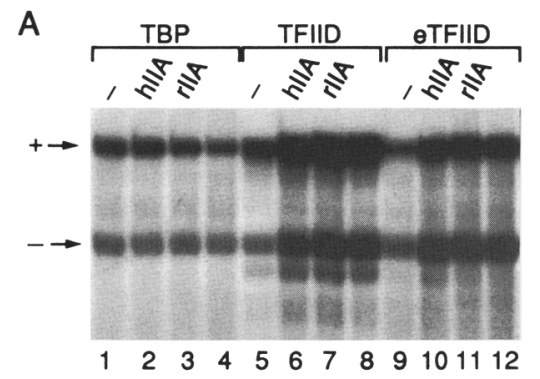

B

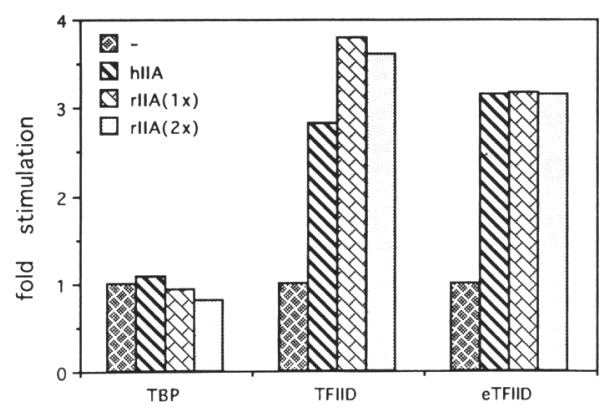

Figure 7. TFIIA stimulates basal transcription directed by TFIID but not TBP. (A) Transcription reactions contained 200 ng of each of two DNA templates driving transcription of either a 380-nucleotide G-less cassette (+ transcripts) or one of 260 nucleotides (- transcripts; see Materials and methods). The sources of TBP/TFIID and TFIIA vary in this experiment, whereas the other GTFs are present in all reactions in saturating amounts. In lanes 1-4, yTBP was added to the reactions (20 ng), lanes 5-8 represent transcription directed by a crude preparation of hTFIID (DE52 fraction, $20 \mathrm{ng}$ of TBP as determined by Western blot), and in lanes 9-12 affinity-purified human eTFIID was added to the reactions $(\sim 25 \mathrm{ng}$ of TBP as determined by Western blot). As for TFIIA, - above the lane indicates no TFIIA was added to the reaction (lanes 1,5,9), whereas hIIA denotes the addition of native TFIIA (DEAE-5PW fraction, $0.3 \mu \mathrm{g}$, lanes $2,6,10)$. rIIA refers to the addition of $0.9 \mu \mathrm{g}(1 \times)$ or $1.8 \mu \mathrm{g}$ $(2 \times)$, respectively, of recombinant $\alpha / \beta+\gamma$ TFIIA (lanes $3,7,11$ and $4,8,12$, respectively|. The products of the reactions were separated by electrophoresis through a $5 \%$ polyacrylamide-urea gel. The dry gel was exposed to an X-ray film for $5 \mathrm{hr} .(B)$ Quantitation of the results in $A$. Numbers on the $y$-axis indicate the fold level of stimulation of the signal in the + band due to the addition of either native TFIIA (hTFIIA) or recombinant TFIIA (rIIA) in the presence of different sources of TBP/TFIID. Signals were quantitated using a PhosphorImager, corrected for background, and plotted relative to transcription levels in the assay in the absence of added TFIIA $(-$, lanes $1,5,9)$.

transcription through some components of the TFIID complex.

\section{TFIIA enhances VP16-mediated activation in vivo and in vitro}

Next, we analyzed whether TFIIA could stimulate VP16mediated transcription activation in vitro. The in vitro transcription reactions in Figure $8 \mathrm{~B}$ all contain GAL4-
VP16, in addition to the components required for basal and activated transcription (see Materials and methods). In this experiment, transcription activation is assessed by comparing the ratio of the activity of the template that is responsive to the activator (+ transcripts) to that of the template that is not responsive (- transcripts). In transcription reactions lacking the activator, this ratio is approximately 1:1 (see Fig. 7A and Fig. 8D, lanes 1,3,5). The addition of Gal4-VP16 to an assay reconstituted in the absence of TFIIA resulted in eightfold activation of transcription (see Fig 8, B, lanes 1 and 5, and D). The addition of human or recombinant TFIIA resulted in three- to fourfold stimulation of transcription independent of whether partially purified TFIID or highly purified eTFIID was used (Fig 8B,C). A quantitative comparison of the ratio of $+1-$ transcripts in the presence or absence of GAL4-VP16 with and without TFIIA is shown in Figure 8D. This figure illustrates that either native or recombinant TFIIA substantially increase the extent of activation by GAL4-VP16.

To further analyze the role of TFIIA in activation of transcription, we studied its effect in vivo using a transient expression assay. A reporter plasmid directing transcription of luciferase and containing five Gal4 DNAbinding sites upstream of the TATA motif was cotransfected with plasmids expressing Gal4-VP16 and the different subunits of TFIIA (p56 and $\gamma$ ) into HeLa cells. We found that at suboptimal concentrations of activator (Gal4-VP16), TFIIA could enhance activation to levels similar to those observed with higher concentrations of Gal4-VP16 (Fig. 8E, cf. lane 3 with lanes 7 and 4). TFIIAmediated enhancement of activation required both the p56 and the $\gamma$ subunits (Fig. 8E, lanes 5-9). Expression of TFIIA in the absence of the activator was without effect or has a modest inhibitory effect (lanes 10-12). These results are in perfect agreement with the in vitro results, indicating that TFIIA enhances the response to the activator (Fig. 8, cf. D and E).

\section{Discussion}

In these studies we report the isolation of a human cDNA clone encoding the $\gamma$-subunit of TFIIA and the reconstitution of TFIIA activity with recombinant polypeptides. We demonstrated that the isolated cDNA clone encodes the $\gamma$-subunit of TFIIA by various methods. First, antibodies raised against the recombinant polypeptide recognize the $13-\mathrm{kD}$ subunit of native human TFIIA. Second, the amino acid sequence of the human cDNA clone shows extensive homology to the yeast TOA2 gene, which encodes a subunit of yeast TFIIA (Ranish et al. 1992) and the Drosophila TFIIA small subunit (Yokomori et al., this issue). Finally, TFIIA binding and transcriptional activity was reconstituted when recombinant $\gamma$-subunit protein was mixed with the other subunits.

Human TFIIA activity is composed of three subunits (Cortes et al. 1992; Coulombe et al. 1992; DeJong and Roeder 1993; Ma et al. 1993; Yokomori et al. 1993a). We, and others previously reported the isolation of a cDNA 


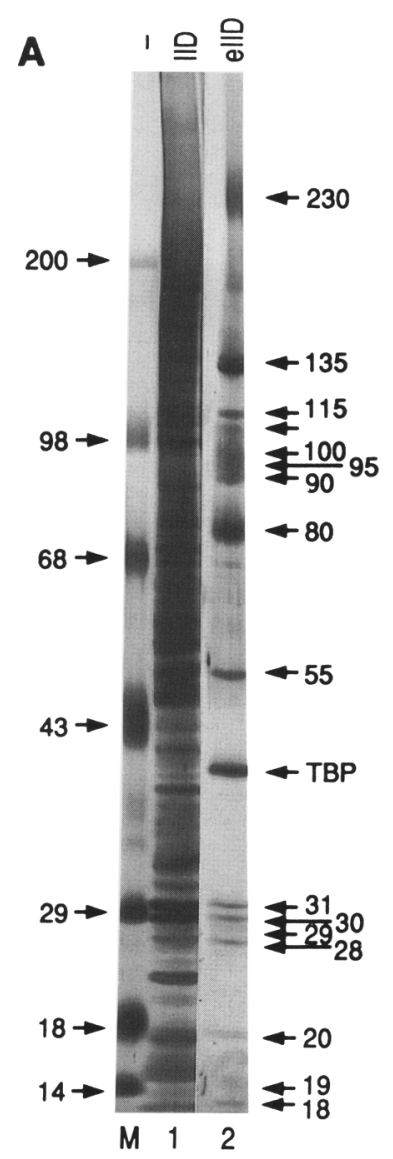

D

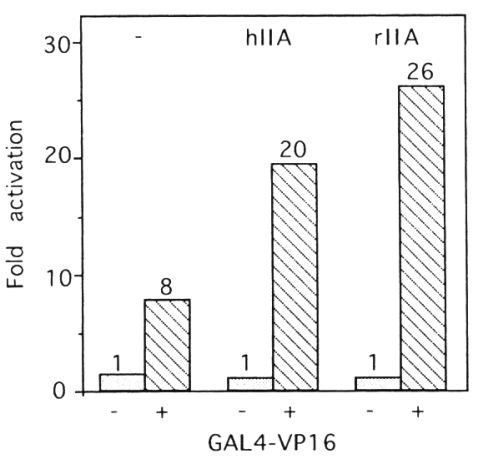

B
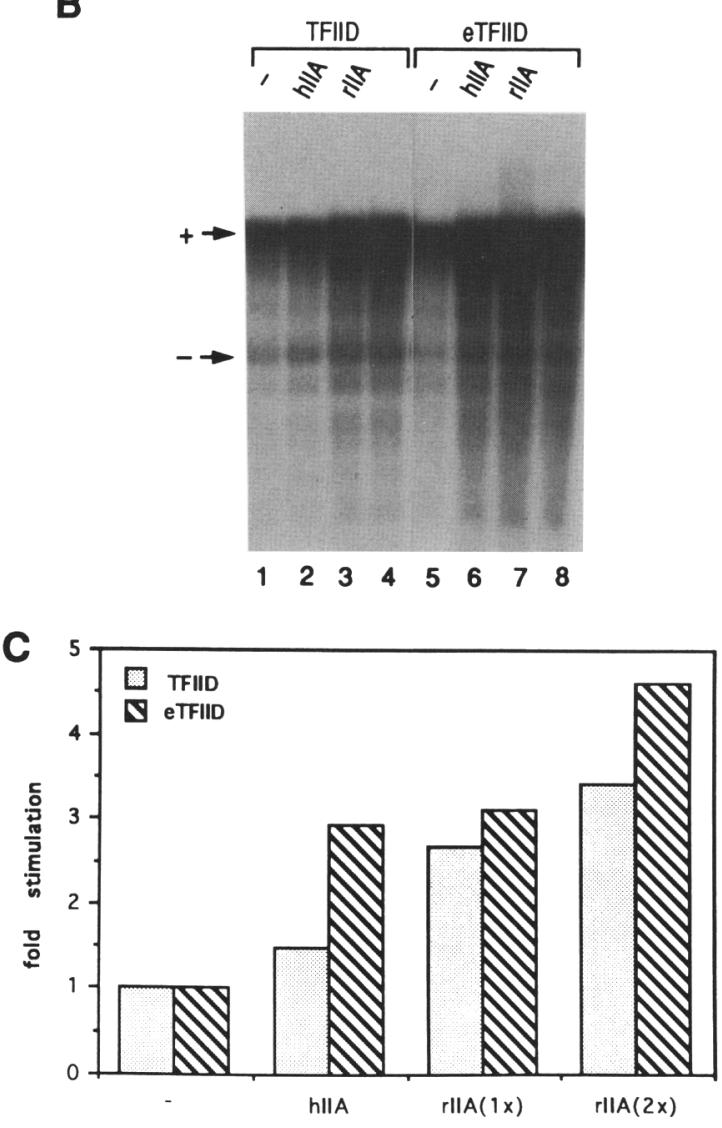

E

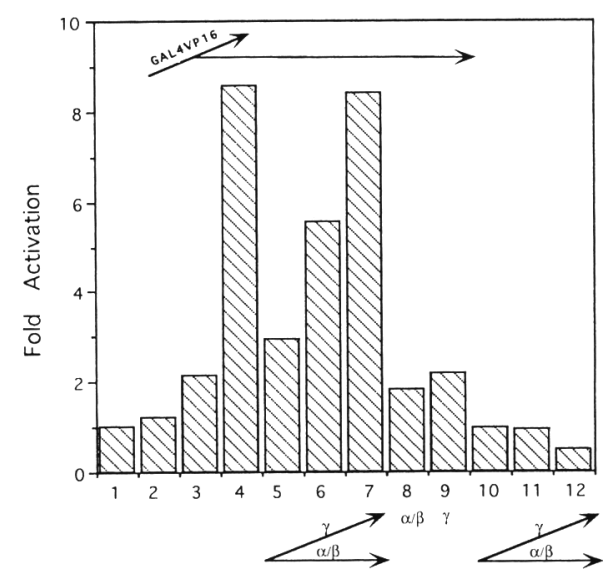

Figure 8. TFIIA stimulates activated transcription directed by crude and highly purified TFIID. (A) Silver stain of an SDSpolyacrylamide gel showing the high degree of purification obtained by immunoaffinity chromatography of eTFIID (see Materials and methods for details). Compare the pattern in lane 1 (crude TFIID, 10 $\mu \mathrm{g}$ ) to that in lane 2 (affinity-purified eTFIID, $\sim 200 \mathrm{ng}$ ). The molecular weights of previously described TAFs are indicated to the right of lane 2 (Chiang et al. 1993). Protein molecular weight standards were run in lane $m$. (B) Native and recombinant TFIIA stimulate GAL4-VP16 activation. All transcription reactions are constituted as described in Fig. 7A, with the exception of two additional components. All the reactions contain $20 \mathrm{ng}$ of GAL4-VP16, as well as a "coactivator mix" that consists of USA and other fractions that will be described elsewhere (J. Inostroza, M. Sheldon, and D. Reinberg, in prep.). As in Fig. 7A, - above the lane indicates no TFIIA was added to the reaction (lanes 1,5); hIIA denotes the addition of native TFIIA [DEAE-5PW fraction $(0.3 \mu \mathrm{g})$ lanes 2,6 ] and rIIA refers to the addition of $0.9 \mu \mathrm{g}$ $(1 \times)$ or $1.8 \mu \mathrm{g}(2 \times)$, respectively, of recombinant $\alpha / \beta+\gamma$ TFIIA (lanes 3,4, and 7,8, respectively). The products of the reactions were separated by electrophoresis through a $5 \%$ polyacrylamide-urea gel. The dry gel was exposed to an X-ray film for 1 hr. (C) Quantitation of the results in B. Numbers on the $y$-axis indicate the fold level of stimulation of the signal in the + band due to the addition of either native TFIIA (hTFIIA) or recombinant TFIIA (rIIA) in the presence of crude or affinity-purified eTFIID. Signals were quantitated using a PhosphorImager, corrected for background, and plotted relative to transcription levels in the assay in the absence of added TFIIA (-, lanes 1,5). (D) Quantitation of the levels of transcriptional activation achieved in $B$. Numbers on the $y$-axis indicate the fold level of activation by GAL4-VP16 and were generated by calculating the ratio of the signal in the + band ("activated" template, containing five GAL4-binding sites) to that of the - band ("basal" template, lacking GAL4binding sites). The data points in which GAL4-VP16 is absent are taken from the transcription shown in Fig. 7A. The transcription reactions in Fig. 7A and B (above) were performed at the same time, run on the same gel, and analyzed by PhosphorImager together. The exposure of Fig. 7A was for $5 \mathrm{hr}$; the exposure of $B$ (above) was for $1 \mathrm{hr}$. (E) TFIIA enhances VP16-mediated activation of transcription in vivo. HeLa cells were cotransfected with $1.5 \mu \mathrm{g}$ of $5 \mathrm{XGal-ML}$ luciferase reporters and increasing amount $(1,3$, and $5 \mathrm{ng}$ ) of Gal4-VPl6 expression vector DNA (lanes 2-4, respectively). In lanes 5-7, cells were cotransfected with $3 \mathrm{ng}$ of Gal4-VP16, $25 \mathrm{ng}$ of CMV-TFIIA- $\alpha / \beta$, and increasing amounts $\{5,15$, and $25 \mathrm{ng}$, respectively) of CMVTFIIA- $\gamma$. In lanes 8 and 9, cells were transfected with $3 \mathrm{ng}$ of GAL4-VP16 and either with CMV-TFIIA- $\alpha / \beta$ (25 ng) or CMV-TFIIA $\gamma$ (25 ng). In lanes 10-12 cells were transfected with the same amount of CMV-TFIIA as in lanes 5-7 but in the absence of Ga14-VP16. Forty-eight hours after transfection, cells were harvested and the cell extracts assayed for luciferase activity. Luciferase activity of extract from cells transfected with promoters alone was arbitrarily set as 1 (lane 1). The effect of TFIIA on Gal4-VP16 transactivation is presented as fold activation. 
clone encoding the largest subunit of TFIIA (De)ong and Roeder 1993; Ma et al. 1993; Yokomori et al. 1993a). Those studies revealed that the two largest subunits are encoded by a single gene and are likely generated by protein processing. In our attempts to reconstitute TFIIA activity, we found that the $\alpha / \beta$ precursor polypeptide, p56, together with the $\gamma$-subunit, could recapitulate TFIIA-binding activity. However, under these particular assay conditions (TA complex formation), the activity of this TFIIA complex was much lower than that of the native factor. Reconstitution of binding activity with the precursor p56 polypeptide required that the protein be denatured and renatured in the presence of p13. These observations led us to attempt to reconstitute TFIIA activity with individual subunits. Because the in vivo cleavage site in p56 is unknown, we artificially generated the $\alpha$ and $\beta$ polypeptides based on protein sequences. Reconstitution with "individual subunits" resulted in a form of TFIIA with a higher activity approaching that of the native factor. These conditions, however, yielded a number of TBP-dependent DNA-protein complexes (TA complexes) on native polyacrylamide gels. The migration of these TBP-dependent DNA-protein complexes was a function of the order of addition of the TFIIA subunits as well as the subunit composition. In some instances, an incomplete TA complex, apparently missing the $\alpha$-subunit, was detected. Interestingly, the aberrantly migrating TA complexes are not unique to recombinant TFIIA. Human TFIIA can be resolved into different forms by gel filtration chromatography that produced TA complexes with altered migrations (D.M. $\mathrm{Ma}$ and D. Reinberg, unpubl.). The studies of DeJong and Roeder (1993) also identified TA complexes with altered mobilities. Earlier studies by Samuels and Sharp (1986) and Coulombe et al. (1992), in which TFIIA was isolated from calf thymus demonstrated that the activity copurified with only two subunits with masses of 19 and 13 $\mathrm{kD}$. The TBP-dependent complex formed with purified calf thymus TFIIA produced a TA complex that migrated faster than the complex formed with native human TFIIA (Coulombe et al. 1992).

It is clear that the TA complex can vary in its migration on native gels as a result of conformational changes or subunit composition. Notwithstanding the possibility that both processes contribute to TA complex formation, it is reassuring that the protein-protein interaction analysis is consistent with our results obtained using the gel mobility shift assay. Using immunoprecipitation studies we found that p56 and the $\gamma$-subunit can independently interact with TBP. When the three individual TFIIA subunits were analyzed for binding and protein-protein interactions, we observed that while $\gamma$ and $\beta$ could form a TBP-dependent DNA complex in the absence of $\alpha$, the individual subunits were incapable of forming a complex on their own. The $\alpha$-subunit appears to enter the TA complex via a direct and specific interaction with the $\gamma$-subunit. Thus, $\gamma$ and $\beta$ can act in concert to stabilize a TBP-dependent complex while $\gamma$ can recruit the $\alpha$ component to complete the formation of the TA complex in vitro. We have not ruled out the possibility that our syn- thetic $\alpha$-subunit lacks amino acids that confer upon the native $\alpha$-subunit the ability to interact with TBP.

\section{TFIIA and transcription}

Earlier studies (Usuda et al. 1991; Cortes et al. 1992; Coulombe et al. 1992/ demonstrated that TFIIA interacts with the TBP. Despite the fact that an interaction between TBP and TFIIA could be demonstrated, we have consistently observed that transcription reactions reconstituted with TBP are unaffected by TFIIA (Fig. 7, also see Cortes et al. 1992; Ma et al. 1993; Merino et al. 1993). In contrast, transcription assays reconstituted with TFIID (in lieu of TBP) exhibit stimulation by TFIIA. These observations led us to postulate the existence of factors in the TFIID complex that negatively modulate transcription (Cortes et al. 1992). Because this initial hypothesis was formulated, factors that interact with TBP and repress transcription have been isolated in human (Meisterernst and Roeder 1991; Meisterernst et al. 1991; Inostroza et al. 1992; Merino et al. 1993) and yeast (Auble and Hahn 1993) cells. Moreover, the interaction between the negative components and TBP appears to be in competition with TFIIA (Meisterernst and Roeder 1991; Meisterernst et al. 1991; Auble and Hahn 1993; Merino et al. 1993). The use of a crude TFIID protein fraction in these earlier studies hampered our attempts to define the precise roles of TFIIA in transcription. The incorporation of highly purified eTFIID (Zhou et al. 1992) and recombinant TFIIA into our highly purified transcription system allowed us to reanalyze the role of TFIIA in transcription. Consistent with the earlier observations, we found that native or recombinant TFIIA has no role in transcription reconstituted with TBP. However, we have observed that transcription reactions reconstituted with highly purified eTFIID are significantly stimulated by native or recombinant TFIIA. The extensive washing of the TFIID complex prior to elution from the antibody column excluded the possibility that factors, other than TAFs, remained associated with the TFIID complex. Our findings suggest that a TAF(s) may down-regulate (repress| basal transcription or that, in the presence of TFIIA, TAF(s) can stimulate basal transcription. We observed that when transcription reactions were reconstituted with either eTFIID or TBP /using approximately equal amounts of TBP-reacting material), the levels of transcription in the absence of TFIIA were similar. This finding strongly argues against the simple model of down-regulation of transcription by $\mathrm{TAF}(\mathrm{s})$ that is neutralized by TFIIA. Because the other components of the reactions were identical, we concluded that TFIIA enhances TFIID-mediated transcription through TAFs. This result is supported by the findings of Yokomori et al. (1993a), demonstrating an interaction of TFIIA with TAF $_{\text {II }} 110$.

During our analyses of the role of TFIIA in transcription we found that recombinant TFIIA also stimulated VP16-mediated activation of transcription. This was observed in vitro as well as in vivo in transfected HeLa cells. TFIIA-mediated stimulation of activated transcrip- 
tion is perhaps not surprising because TFIIA can enhance TFIID-dependent basal transcription. However, we observed that TFIIA also enhanced the net fold of activation. Therefore, it appears that the effect of TFIIA on VP16-mediated activation is not simply attributable to enhancement of basal transcription, but rather, TFIIA seems to directly participate in the activation process.

The effect of TFIIA on activation of transcription was not specific for Gal4-VP16. We found that activation by a glutamine-rich activator was also stimulated by TFIIA in vitro. When we analyzed the Epstein-Barr viral activator Zta we confirmed the previous observations indicating a requirement for TFIIA (Chi and Carey 1993; Lieberman and Berk 1994) However, we discovered that one of the coactivators required for optimal activation by Gal4-VP16 had a strong inhibitory effect on Zta activation (M. Sheldon and D. Reinberg, unpubl.). Together, these studies suggest that TFIIA enhances activation of transcription but that the mechanism by which it operates may be diverse.

The TFIIA-mediated stimulation of transcription (basal and activated) requires the three subunits of TFIIA. Quite surprisingly, we did not detect any difference in transcription activity between TFIIA reconstituted with the p56 and $\gamma$ subunits versus the individual subunits (M. Sheldon and D. Reinberg, unpubl.). These observations are incongruent with our analysis of TA complex formation. Perhaps TA complex formation and TFIID-dependent transcription measure different functions of TFIIA. This is supported by observations indicating that in functional transcription assays, TFIIA does not stably associate with the preinitiation complex but, rather, appears to act catalytically (L. Zawel and D. Reinberg, unpubl.).

The requirement of TFIIA in transcription has been a controversial subject. While it has now become clear that TFIIA is important for transcription, its precise role(s) remain to be elucidated. The availability of recombinant TFIIA and the development of transcription assays reconstituted with defined components will help to decipher the role of TFIIA.

\section{Materials and methods}

\section{Purification of TFIIA}

TFIIA was purified from the phosphocellulose $0.1 \mathrm{M} \mathrm{KCl}$ protein fraction (Reinberg et al. 1987) as described previously by Cortes et al. (1992). Both a functional transcription assay and the ability of TFIIA to affect the binding of TBP to the TATA motif using the gel mobility shift assay were employed during purification of native TFIIA.

\section{Molecular cloning of the small subunit of TFIIA}

The amino acid sequences of Drosophila small subunit of TFIIA (gift of Dr. R. Tjian) and TOA2 (Ranish et al. 1992) were compared, and the two regions displaying the highest degree of homology were selected. The amino acid sequences of these two regions in Drosophila are TYRFCDNVWT and DKVKIVA. Two degenerate oligonucleotides derived from these two peptide sequences were synthesized: 5 '-ACNTAT/CCGCTTT/CTGT/ CGAT/CAAT/CGTNTGGAC-3' ; and 5'-ACA/T/GATT/CT-
TNACT/CTTA/GTC-3' $(N=\mathrm{A}, \mathrm{C}, \mathrm{G}, \mathrm{T})$. A mixture containing the degenerate oligonucleotide was used to screen a HeLa $\lambda \mathrm{ZA}$ PII cDNA library (Stratagene). After a second round of screening, seven positive plaques were chosen for sequencing. The longest cDNA with an open reading frame encoding the small subunit of TFIIA is shown in Figure 1A.

\section{Expression of recombinant TFIIA- $\gamma$}

Two oligonucleotides were synthesized $\left(5^{\prime}\right.$-ATATATCATATGGCATATCAGTTATAC-3' and 5'-ATATATGGATCCTCATTCTGTAGTATTGG-3'), and DNA fragments encoding the TFIIA- $y$ were amplified using the polymerase chain reaction (PCR). The DNA fragments were inserted between the NdeI and BamHI sites of pET15b vector (Novogene). E. coli cells were transformed and expression induced with IPTG $(0.4 \mathrm{~mm})$. The induced His-tagged protein was purified using affinity chromatography on Ni-NTA columns according to Qiagen's specifications. Under these conditions, TFIIA- $\gamma$ was partially soluble. Under native conditions, the protein was eluted from the $\mathrm{Ni}$ NTA column with $200 \mathrm{~mm}$ imidazole.

\section{Purification of rTFIIA- $\alpha / \beta$, rTFIIA $-\alpha$, and rTFIIA- $\beta$} polypeptides

DNA fragments encoding the $\alpha / \beta, \alpha$, and $\beta$ subunits of TFIIA were obtained by PCR and cloned into pET21a|+|(Novogene) between the BamHI and HindIII sites. The corresponding constructs are called pET21a $|+|-\alpha / \beta, \quad$ EET2 $1 \mathrm{a}|+|-\alpha$, and pET2la $\mid+1-\beta$. The recombinant proteins were purified by one step using Ni-NTA chromatography under denaturing conditions as described by the manufacturer. Polypeptides were renatured by dialysis against buffer BC-100 $(20$ mM HEPES at $\mathrm{pH} 7.9$, $10 \%$ glycerol, $0.1 \mathrm{M} \mathrm{KCl}, 1 \mathrm{~mm}$ DTT, $0.2 \mathrm{~mm}$ PMSF, $0.1 \mathrm{~mm}$ EDTA). Different combination of subunits were mixed in equal molar ratio (or modified as indicated on experiments). The polypeptides were completely denatured and renatured by dialysis against buffer C-100.

Antibodies against TFIIA- $\gamma$, TFIIA- $\alpha$, TFIIA- $\boldsymbol{\beta}$, and TFIIA- $\alpha / \beta$

Recombinant His-tagged TFIIA- $\gamma$, TFIIA- $\alpha$, TFIIA- $\beta$, and TFIIA$\alpha / \beta$ were purified and dialyzed extensively against PBS. Proteins were mixed in a $1: 1$ ratio with complete Freund's adjuvant and injected into rabbits. Three weeks after the first injection, another injection was given with incomplete Freund's adjuvant.

\section{Gel mobility shift assay}

DNA-binding assays were performed as described previously (Maldonado et al. 1990). DNA fragments containing the adenovirus major late promoter, Gal4-binding site, or the YY1-binding site (derived from the $\beta$-DNA polymerase promoter (L. Weis and D. Reinberg, in prep.) was added to $\sim 1$ fmole (4000 cpm). DNA-protein complexes were separated on a $5 \%$ polyacrylamide gel. Protein factors were added as indicated in the figures. In the supershift experiment, antibodies were purified by protein A beads (Sigma) and dialyzed against buffer C-100. Antibodies $(1 \mu \mathrm{l}, \sim 0.5 \mu \mathrm{g})$ were added at completion of the DNAbinding assay (after $30 \mathrm{~min}$ at $30^{\circ} \mathrm{C}$ ). Samples were incubated further for $15 \mathrm{~min}$ at $30^{\circ} \mathrm{C}$. Reactions were stop by loading the samples on the gel. 


\section{Coimmunoprecipitation and Western blot analysis}

Monoclonal antibodies against human TBP or protein A purified anti-TFIIA- $\gamma$ antibodies were incubated with $10 \mu l$ of packed protein A-Sepharose beads (Sigma) for $1 \mathrm{hr}$ at room temperature. Then $200 \mu$ l of IP buffer (Tris- $\mathrm{HCl}$ buffer at $\mathrm{pH} 7.9,100 \mathrm{mM}$ $\mathrm{NaCl}, 1 \% \mathrm{NP}-40,1 \mathrm{~mm}$ PMSF, and $1 \mathrm{~mm}$ DTT) and either human TBP $(250 \mathrm{ng})$ or rTFIIA- $\gamma(250 \mathrm{ng})$ were added and samples incubated at $4^{\circ} \mathrm{C}$ for $1.5 \mathrm{hr}$. Then $250 \mathrm{ng}$ of the secondary proteins (TFIIA- $\alpha / \beta$, TFIIA- $\boldsymbol{\gamma}$, TFIIA- $\alpha$, or TFIIA- $\beta$ ) was added and further incubated at $4^{\circ} \mathrm{C}$ for $2.5 \mathrm{hr}$. Beads were washed thoroughly with IP buffer containing a different salt concentration, as indicated in the figure legends. Samples were then eluted from the protein A beads with $1.0 \mathrm{M}$ glycine $(\mathrm{pH} 2.6)$. Samples were then neutralized with Tris, boiled for $5 \mathrm{~min}$ in Laemmli sample buffer, and subjected to SDS-PAGE. The signals were visualized by Western blot using antibodies against the different proteins, as indicated on the figure legends.

\section{Immunoaffinity purification of eTFIID}

A column containing $5 \mathrm{mg}$ of $12 \mathrm{CA} 5$ monoclonal antibodies $/ \mathrm{ml}$ of protein A-agarose was prepared as described (Harlow and Lane 1988). Nuclear extracts made from LTR $3 \alpha$ cells that express epitope-tagged holo-TFIID (Zhou et al. 1992) were prepared as described. The extract $(\sim 1.0$ liter of sample with a protein concentration of $\sim 6-8 \mathrm{mg} / \mathrm{ml}$ ) was fractionated by chromatography on phosphocellulose and DEAE-cellulose as described for the fractionation of the HeLa cell extracts. eTFIID fractionated with endogenous TFIID. Approximately $200 \mu \mathrm{l}$ of the mAb 12CA5 resin was then incubated with $10-50 \mu \mathrm{g}$ of epitope-tagged holo-TFIID sample. The incubation was done at $4^{\circ} \mathrm{C}$ for $8 \mathrm{hr}$ in buffer $\mathrm{C}$ containing $25 \mathrm{~mm}$ Tris- $\mathrm{HCl}(\mathrm{pH} 7.9)$, $10 \%$ glycerol, $0.2 \mathrm{~mm}$ EDTA, $0.1 \mathrm{~mm}$ PMSF, and $1.0 \mathrm{M} \mathrm{KCl}$. After incubation, the mAb $12 \mathrm{CA} 5$ resin was transferred to a 10-ml Bio-Rad column and washed with 10-20 column volumes of ice-cold buffer $\mathrm{C}$ containing $1.0 \mathrm{M} \mathrm{KCl}$. eTFIID was eluted with $400 \mu \mathrm{l}$ of BC- 1000 (pH 7.9) containing $5 \mathrm{mg} / \mathrm{ml}$ of the $\mathrm{mAb}$ $12 \mathrm{CA} 5$ peptide. The buffer was prewarmed at $30^{\circ} \mathrm{C}$, and the $\mathrm{pH}$ was adjusted to 7.9 under these conditions. The protein and buffer were incubated at $30^{\circ} \mathrm{C}$ for $15 \mathrm{~min}$. At that point, the eluted eTFIID was collected in a single fraction. Subsequently, the column was eluted twice with $400 \mu \mathrm{l}$ of BC-1000 $(\mathrm{pH} 7.9)$ without peptide and 400- $\mu$ l fractions were collected. eTFIID generally eluted in the first and second fractions.

\section{In vitro transcription assays}

Basal transcription Transcription reactions were performed essentially as described (Flores et al. 1992), using a fractionated HeLa transcription system containing $200 \mathrm{ng}$ of each of the DNA molecules. Transcription factors added to the reaction were native TFIIA/J (DEAE-5PW fraction, $0.3 \mu \mathrm{g}$ ) or recombinant TFIIA- $\alpha / \beta+\gamma(0.9$ and $1.8 \mu \mathrm{g}: 1 \times$ and $2 \times$, respectively. $)$, recombinant TFIIB (S-Sepharose, $20 \mathrm{ng}$ ), recombinant yeast TBP S-Sepharose, $100 \mathrm{ng}$, purified as described previously (Maldonado et al. 1990), or native human TFIID, [DEAE-cellulose (DE52) fraction], or affinity-purified eTFIID (see above). Recombinant TFIIE and TFIIF (10 ng each) were purified as described (Lu et al. 1991). Native TFIIH (phenyl Superose fraction, $400 \mathrm{ng}$ ) and RNA polymerase II (alkyl Superose fraction, $60 \mathrm{ng}$ ) were used. Two plasmids were used as templates in the transcription assays: pG5MLT contains the adenovirus major late promoter driving a transcript from a 380-nucleotide G-less cassette and has five tandem copies of the Gal4 DNA-binding site upstream of the promoter (Merino et al. 1993). p $\Delta M L$ also contains the adenovirus major late promoter but driving a G-less cassette of shorter length (260 nucleotides) and lacking upstream Gal4 sites.

Transcription reaction mixtures $(40 \mu 1)$ were incubated for 60 min at $30^{\circ} \mathrm{C}$ after which time the RNA products were extracted with phenol/chloroform, ethanol precipitated, resolved on a $6 \%$ polyacrylamide-urea gel, and visualized by autoradiography. Results were quantitated using a Bio-Rad PhosphorImager and analysis software.

Activated transcription For the transcription activation assays, GAL4-VP16 was expressed in E. coli as a histidine-tagged protein and purified by nickel affinity chromatography as described previously (Abate et al. 1990). Twenty nanograms of the resultant protein $(>90 \%$ pure) was added to each transcription reaction. To obtain optimal levels of transcriptional activation, two fractions were added to reactions that contained all the components of the basal transcription assay. The first of these, upstream stimulatory activator (USA), was purified from the phosphocellulose $1 \mathrm{M}$ fraction as described previously (Meisterernst et al. 1991). The second is an activity (coactivator A) present in the phosphocellulose $0.1 \mathrm{M}$ fraction that is required to achieve optimal levels of activation when highly purified native TFIIA or recombinant TFIIA are used (J. Inostroza, M. Sheldon, and D. Reinberg, in prep.). Results were quantitated using a Bio-Rad PhosphorImager and analysis software. To control for possible contamination of the - signal by the + signal above it in the lane, a background band just above the - band and below the + band was quantitated and subtracted from the - signal.

\section{Plasmid constructs for transfection}

CMVTFIIA- $\gamma$ was constructed by PCR with oligonucleotide $5^{\prime}$ GCGCGGATCCATGGCATATCAGTTATAC-3' and 5'-GCGCTCTAGATCATTCTGTAGTATTGGAGC-3' (the underlined nucleotides indicate $B a m H I$ and $X b a I$ sites, respectively). The PCR product was cloned into The BglII and $X b a I$ sites of a cytomegalovirus (CMV) expression vector CMV5 (gift of Dr. Mark Stinski, University of Iowa, Iowa City). CMV-TFIIA- $\alpha / \beta$ was constructed by inserting the cDNA of human TFIIA- $\alpha / \beta$ /a BamHI-SalI fragment) into the Bg/II and SalI sites of CMV5. Expression vector Gal4-VP16 and reporter construct 5XGalML-LUC have been described previously (Yueng et al. 1994).

\section{Transfection and luciferase assay}

HeLa cells were grown in Dulbecco's minimal essential medium supplemented with $10 \%$ defined calf serum. Cells were plated on $35-\mathrm{mm}$ dishes and transfected at $70-80 \%$ confluence with lipofectamine according to manufacturer specifications (BRL). A total of $2 \mu \mathrm{g}$ of DNA and $2 \mu \mathrm{g}$ of lipofectamine were used per plate. Each transfection was performed no less than three times. Cells were harvested $48 \mathrm{hr}$ after transfection, and total cell extracts were assayed for luciferase actvity with a kit purchased from Promega.

\section{Acknowledgments}

We thank Drs. R. Tjian, M.P. Zeidler, and M. Mlodzik for making the amino acid sequence of the Drosophila TFIIA- $\gamma$ subunit available prior to publication. We also thank Dr. S. Hahn for communicating results before publication. We thank Dr. N. 
Hernandez for the gift of monoclonal antibodies against human TBP. We also thank J.A. Inostroza for providing eTFIID and making available Figure 8A. We thank Drs. L. Vales, R. Drapkin, R. Shiekhattar, and L. Zawel for reading of the manuscript. This work was supported by grants from National Institutes of Health (NIH) to D.R.M.S. was supported by an NIH fellowship (CA 62590). D.R. was a recipient of an American Cancer Society Faculty Research Award.

The publication costs of this article were defrayed in part by payment of page charges. This article must therefore be hereby marked "advertisement" in accordance with 18 USC section 1734 solely to indicate this fact.

\section{References}

Abate, C., D. Luk, R. Gentz, F.J. Rauscher, and T. Curran. 1990. Expression and purification of the leucine zipper and DNA binding domains of Fos and Jun: Both Fos \& Jun contact DNA directly. Proc. Natl. Acad. Sci. 87: 1032-1036.

Auble, D. and S. Hahn. 1993. An ATP-dependent inhibitor of TBP binding to DNA. Genes \& Dev. 7: 844-856.

Auble, D.T., K.E. Hansen, C.G.F. Mueller, W.S. Lane, J. Thorner, and S. Hahn. 1994. Mot1, a global repressor of RNA polymerase II transcription, inhibits TBP binding to DNA by an ATP-dependent mechanism. Genes \& Dev. 8: 1920-1934.

Buratowski, S., S. Hahn, L. Guarente, and P. Sharp. 1989. Five intermediate complexes in transcription initiation by RNA polymerase II. Cell 56: 549-561.

Chi, T.H. and M. Carey. 1993. The ZEBRA activation domain: Molecular organization and mechanism activation. Mol. Cell. Biol. 13: 7045-7055.

Chiang, C.-M., H. Ge, Z.X. Wang, A. Hoffmann, and R. Roeder. 1993. Unique TATA-binding protein-containing complexes and cofactors involved in transcription by RNA polymerases II and III. EMBO /. 12: 2749-2762.

Choy, B. and M. Green. 1993. Eukaryotic activators function during multiple steps of preinitiation complex assembly. Nature 366: 531-536.

Cortes, P., O. Flores, and D. Reinberg. 1992. Factors involved in specific transcription by mammalian RNA polymerase II: Purification and analysis of transcription factor IIA and identification of transcription factor IIJ. Mol. Cell. Biol. 12: 413421.

Coulombe, B., M. Killeen, P. Liljelund, B. Honda, H. Xiao, C.J. Ingles, and J. Greenblatt. 1992. Identification of three mammalian proteins that bind to the yeast TATA box protein TFIID. Gene Expression 2: 99-110.

DeJong, J. and R.G. Roeder. 1993. A single cDNA, hTFIIA/a, encodes both the p35 and p19 subunits of human TFIIA. Genes \& Dev. 7: 2220-2234.

Drapkin, R., A. Merino, and D. Reinberg. 1993. Regulation of RNA polymerase II transcription. Curr. Opin. Cell. Biol. 5: 469-476.

Flanagan, J., R. Becker, K. Ennist, Gleason, S. Ennist, P. Driggers, B. Levi, E. Appella, and K. Ozato. 1992. Cloning of a negative transcription factor that binds to the upstream conserved region of Moloney murine leukemia virus. Mol. Cell. Biol. 12: 38-44.

Flores, O., H. Lu, M. Killeen, J. Greenblatt, Z.F. Burton, and D. Reinberg. 1991. The small subunit of transcription factor IIF recruits RNA polymerase II into the preinitiation complex. Proc. Natl. Acad. Sci. 88: 9999-10003.

Flores, O., H. Lu, and D. Reinberg. 1992. Factors involved in specific transcription by mammalian RNA polymerase. II. Identification and characterization of factor IIH. I. Biol.
Chem. 267: 2786-2793.

Gill, G. and R. Tjian. 1992. Eukaryotic coactivators associated with the TATA box binding protein. Curr. Opin. Genet. Dev. 2: 236-242.

Goodrich, J., T. Hoey, C. Thut, A. Admon, and R. Tjian. 1993. Drosophila TAFII40 interacts with both a VP16 activation domain and the basal transcription factor TFIIB. Cell 75: 519-530.

Hahn, S. 1993. Structure and function of acidic transcriptional activators. Cell 72: 481-483.

Hariharan, N., D. Kelley, and R. Perry. 1991. D, a transcription factor that binds to downstream elements in several polymerase II promoters, is a functionally versatile zinc finger protein. Proc. Natl. Acad. Sci. 88: 9799-9803.

Harlow, E. and D. Lane 1988. Immunoaffinity purification. In Antibodies: A laboratory manual. p. 522. Cold Spring Harbor Laboratory, Cold Spring Harbor, New York.

Hoey, T., R.O.J. Weinzierl, G. Grace, J.L. Chen, B.D. Dynlacht, and R. Tiian. 1993. Molecular cloning and functional analysis of Drosophila TAF110 reveal properties expected of activators. Cell 72: 247-260.

Imbalzano, A.N., K.S. Zaret, and R.E. Kingston. 1994. Transcription factor (TF) IIB and TFIIA can independently increase the affinity of the TATA-binding protein for DNA. I. Biol. Chem. 269: 8280-8286.

Inostroza, J.A., F.H. Mermelstein, I. Ha, W.S. Lane, and D. Reinberg. 1992. Drl, a TATA-binding protein-associated phosphoprotein and inhibitor of class II gene transcription. Cell 70: 477-489.

Kephart, D.D., B.Q. Wang, Z.F. Burton, and D.H. Price. 1994. Functional analysis of Drosophila factor 5 (TFIIF), a general transcription factor. J. Biol. Chem. 269: 13536-13543.

Lee, D.K., J. Dejong, S. Hashimoto, M. Horikoshi, and R.G. Roeder. 1992. TFIIA induces conformational changes in TFIID via interactions with the basic repeats. Mol. Cell. Biol. 12: 5189-5196.

Lewin, B. 1990. Commitment and activation at Pol II promoters: A tail of protein-protein interactions. Cell 61: 11611164.

Lieberman, P.M. and A.J. Berk. 1994. A mechanism for TAFs in transcriptional activation: Activation domain enhancement of TFIID-TFIIA-promoter DNA complex formation. Genes \& Dev. 8: 995-1006.

Lin, Y.S., I. Ha, E. Maldonado, D. Reinberg, and M.R. Green. 1991. Binding of general transcription factor TFIIB to an acidic activating region. Nature 353: 569-571.

Lu, H., O. Flores, R. Weinmann, and D. Reinberg. 1991. The nonphosphorylated form of RNA polymerase II preferentially associates with the preinitiation complex. Proc. Natl. Acad. Sci. 88: 10004-10008.

Ma, D.M., H. Watanabe, F.H. Mermelstein, A. Admon, K. Oguri, X. Sun, T. Wada, T. Imai, T. Shiroya, D. Reinberg, and H. Handa. 1993. Isolation of a cDNA encoding the largest subunit of TFIIA reveals functions important for activated transcription. Genes \& Dev. 7: 2246-2257.

Maldonado, E., I. Ha, P. Cortes, L. Weis, and D. Reinberg. 1990. Factors involved in specific transcription by mammalian RNA polymerase II: Role of transcription factors IIA, IID, and IIB during formation of a transcription-competent complex. Mol. Cell. Biol. 10: 6335-6347.

Meisterernst, M. and R.G. Roeder. 1991. Family of proteins that interact with TFIID and regulate promoter activity. Cell 67: 557-567.

Meisterernst, M., A.L. Roy, H.M. Lieu, and R.G. Roeder. 1991. Activation of class II gene transcription by regulatory factors is potentiated by a novel activity. Cell 66: 981-993. 
Merino, A., K.R. Madden, W.S. Lane, J.J. Champoux, and D. Reinberg. 1993. Topoisomerase I is involved in both repression and activation of transcription. Nature 365: 227-232.

Park, K. and M.L. Atchison. 1991. Isolation of a candidate Repressor/Activator, NF-E 1 (YY1, $\delta)$, that binds to the immunoglobulin $\kappa 3^{\prime}$ enhancer and the immunoglobulin heavychain $\mu \mathrm{El}$ site. Proc. Natl. Acad. Sci. 88: 9804-9808.

Pugh, B.F. and R. Tjian. 1990. Mechanism of transcriptional activation by Spl: Evidence for coactivators. Cell 61: 11871197.

Ranish, J. and S. Hahn. 1992. The yeast transcription factor TFIIA is composed of two polypeptide subunits. I. Biol. Chem. 166: 19320-19327.

Ranish, J., W. Lane, and S. Hahn. 1992. Isolation of two genes that encode subunits of the yeast transcription factor IIA. Science 255: 1130-1132.

Reinberg, D., M. Horikoshi, and R.G. Roeder. 1987. Factors involved in specific transcription by mammalian RNA polymerase II. Functional analysis of initiation factors IIA and IID and identification of a new factor operating at sequences downstream of the initiation site. I. Biol. Chem. 262: 33223330.

Ruppert, S., E.D. Wang, and R. Tiian. 1993. Cloning and expression of human TAFI250: A TBP-associated factor implicated in cell cycle regulation. Nature 362: 175-179.

Samuels, M. and P.A. Sharp. 1986. Purification and characterization of a specific RNA polymerase II transcription factor. I. Biol. Chem. 261: 2003-2013.

Shi, Y., E. Seto, L.S. Chang, and T. Shenk. 1991. Transcriptional repression by YY1, a human GLI-Kruppel-related protein, and relief of repression by adenovirus E1A protein. Cell 67: 377-388.

Stringer, K.F., C.J. Ingles, and J. Greenblatt. 1990. Direct and selective binding of an acidic activation domain to the TATA-Box factor TFIID. Nature 345: 783-786.

Tjian, R. and T. Maniatis. 1994. Transcription activation: A complex puzzle with few easy pieces. Cell 77: 5-8.

Usuda, Y., A. Kubota, A. Berk, and H. Handa. 1991. Affinity purification of transcription factor IIA from Hela cell nuclear extracts. EMBO /. 10: 2305-2310.

Verrijzer, C.P., K. Yokomori, J.-L. Chen, and R. Tjian. 1994. Drosophila TAFII150: Similarity to yeast gene TSM-1 and specific binding to core promoter DNA. Science 264: 933941.

Weinzierl, R.O.J., B.D. Dynlacht, and R. Tjian. 1993. The largest subunit of Drosophila TFIID directs assembly of a complex containing TBP and coactivators. Cell 362: 511-517.

Xiao, H., A. Pearson, B. Coulombe, R. Truant, S. Zhang, J.L. Regier, S.J. Triezenberg, D. Reinberg, O. Flores, C.J. Ingles, and J. Greenblatt. 1994. Binding of basal transcription factor TFIIH to the acidic activation domains of VP16 and p53. Mol. Cell. Biol. (in press).

Yokomori, K., A. Admon, J.A. Goodrich, J.-L. Chen, and R. Tiian. 1993a. Drosophila TFIIA-L is processed into two subunits that are associated with the TBP/TAF Complex. Genes \& Dev. 7: 2235-2245.

Yokomori, K., J.-L. Chen, A. Admon, S. Zhou, and R. Tjian. 1993b. Molecular cloning and characterization of $\operatorname{dTAF}_{\mathrm{II}} 30 \alpha$ and dTAF $_{\text {II }} 30 \beta$ : Two small subunits of Drosophila TFIID. Genes \& Dev. 7: 2587-2597.

Yokomori, K., M.P. Zeidler, J.-L. Chen, C.P. Verrijzer, M. Mlodzik, and R. Tjian. 1994. Drosophila TFIIA directs cooperative DNA biding with TBP and mediates transcriptional activation. Genes \& Dev. (this issue).

Yueng, K.C., J.A. Inostroza, F.H. Mermelstein, C. Kannabiran, and D. Reinberg. 1994. Structure-function analysis of TBP- binding protein, $\mathrm{Dr}_{1}$ reveals a mechanism for repression of class II gene transcription. Genes \& Dev. 7: 2097-2109.

Zawel, L. and D. Reinberg. 1993. Initiation of transcription by RNA polymerase II: A multi-step process. Prog. Nucleic Acid Res. Mol. Biol. 44: 67-108.

Zawel, L., H. Lu, L.J. Cisek, J.L. Corden, and D. Reinberg. 1993. The cycling of RNA polymerase II during transcription. Cold Spring Harbor Symp. Quant. Biol 58: 187-198.

Zhou, Q., P.M. Lieberman, T.G. Boyer, and A.J. Berk. 1992. Holo-TFIID supports transcriptional stimulation by diverse activators and from TATA-less promoters. Genes \& Dev. 6: 1964-1974. 


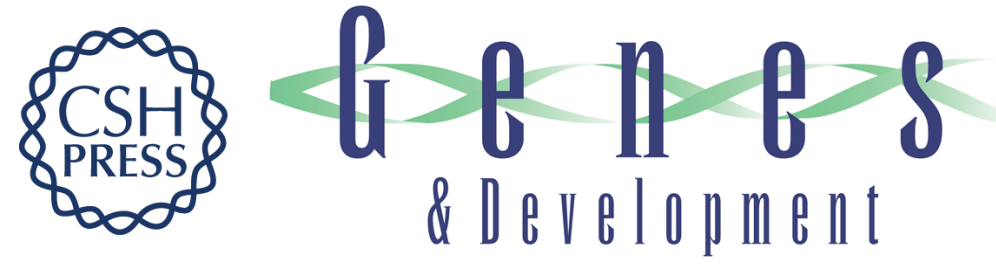

\section{Reconstitution of human TFIIA activity from recombinant polypeptides: a role in TFIID-mediated transcription.}

X Sun, D Ma, M Sheldon, et al.

Genes Dev. 1994, 8:

Access the most recent version at doi:10.1101/gad.8.19.2336

References This article cites 51 articles, 26 of which can be accessed free at:

http://genesdev.cshlp.org/content/8/19/2336.full.html\#ref-list-1

License

Email Alerting

Service

Receive free email alerts when new articles cite this article - sign up in the box at the top right corner of the article or click here.

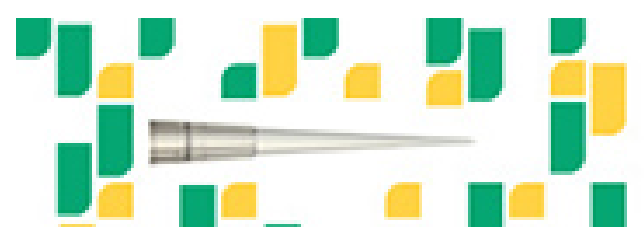

Focused on your science.

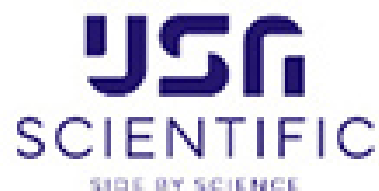

Copyright @ Cold Spring Harbor Laboratory Press 